\title{
Davian behaviour in the threatened California red-legged frog Rana draytonii: more than just a waste of time
}

\author{
JEFF A. ALVAREZ ${ }^{1 *}$, SARAH M. FOSTER ${ }^{2}$, BRANDT R. MULLER ${ }^{3} \&$ CHRISTOPHER D. VANG $^{4}$ \\ ${ }^{1}$ The Wildlife Project, PO Box 188888, Sacramento, California USA 95818 \\ ${ }^{2}$ Foster Wildlife Surveys, 774 5th Avenue, Sacramento, CA 95818 \\ ${ }^{3} 13455$ Roan Court, Sutter Creek, California USA 95685 \\ ${ }^{4} 8480$ Orchard Creek Way, Elk Grove, California USA 95624 \\ *Corresponding author e-mail: jeff@thewildlifeproject.com
}

$D^{2}$ avian behaviour, also variously referred to as necrogamy (Bettaso et al., 2008), necrophilia (Cortés Bedoy et al., 2014), and misdirected copulation (Ayres, 2010), is an event during which a live individual attempts to mate with a dead individual for reproductive gain (Ayres, 2010). This behaviour has been observed in amphibians (Bettaso et al., 2008), reptiles (Costa et al., 2010), birds (Lehner, 1988), and mammals (Dickerman, 1960), but appears to be most common among anurans (Pearl et al., 2005). Alvarez (2011) reported Davian behaviour between a western toad (Bufo boreas) and California red-legged frog (Rana draytonii); that observation, however, would have been more appropriately referred to as interspecific amplexus because neither individual was dead. Herein we report two observations of Davian behaviour in the threatened California red-legged frog.

In 2001, while conducting daytime monitoring surveys to assess reproduction in California red-legged frogs within mitigation wetlands in Contra Costa County, California, USA, the senior author encountered a live adult male California red-legged frog in pectoral amplexus with a dead adult female conspecific (Fig. 1). The pair was photographed but not handled. Amplexus occurred along the water's edge (approximately $5 \mathrm{~cm}$ from the pool edge and in water $2 \mathrm{~cm}$ deep), and adjacent to a patch of cattail (Typha sp.). When encountered, the male was clasped tightly to the female's thoracic region. The female was in a very early state of decomposition, and showed evidence of having been ovipositing at death, or that eggs had been forced outward by the compressive force of the male.

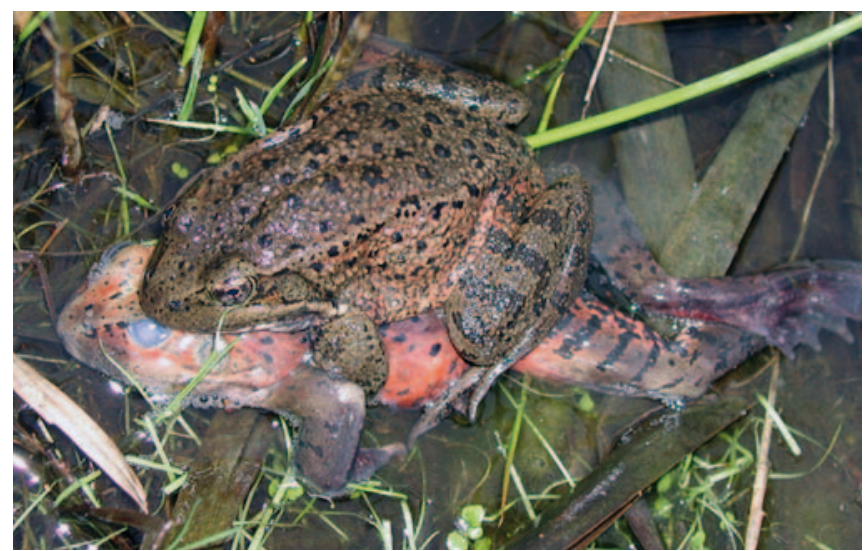

Figure 1. An adult male California red-legged frog engaged in Davian behavior with a dead adult female conspecific in the early stages of decomposition (Contra Costa County, California, 2001)
In 2016, we were again conducting daytime monitoring surveys in a drain adjacent to the first observation when we similarly encountered a live adult male California redlegged frog in pectoral amplexus with a dead adult female conspecific. Amplexus was observed along the water's edge (approximately $30 \mathrm{~cm}$ from the pool edge and in water $20 \mathrm{~cm}$ deep), amidst a patch of dead cattail (Typha sp.). The small adult male was clasped very tightly to the female's thoracic region. The female was partially decomposed, with a thin film of fungal hyphae covering the majority of her body (Fig. 2). Despite handling and photography, the male did not disengage from the female.

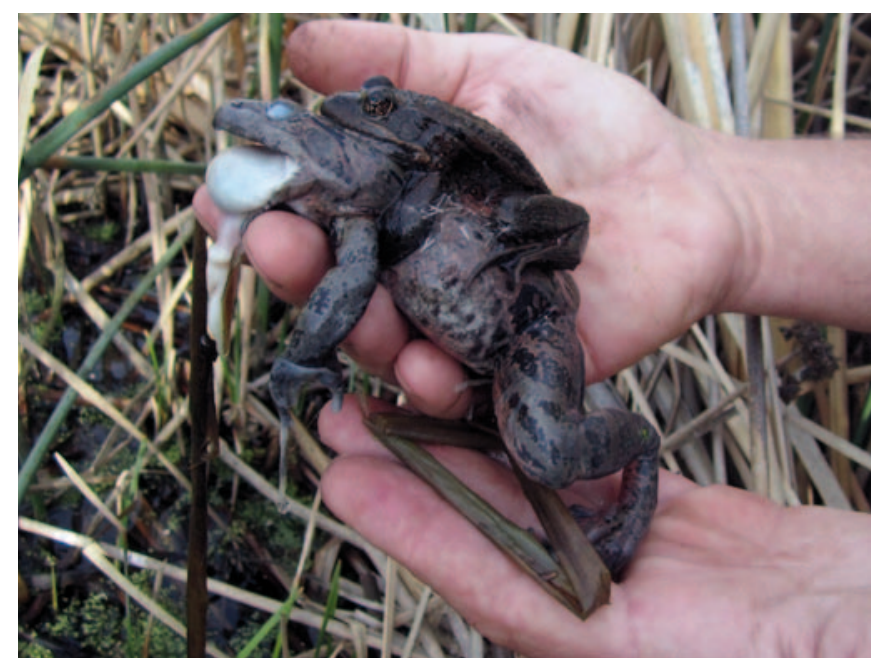

Figure 2. An adult male California red-legged frog engaged in Davian behaviour with a dead adult female conspecific in 2016. The female is partially decomposed and acquiring a film of fungal hyphae.

Davian behaviour has been considered a possible ecological trap because persistent necrophilic males may lose or experience diminished opportunities to successfully reproduce during the (often brief) breeding season (Ayres, 2010). Magnhagen (2003) suggested that the risk of predation may also increase during Davian behaviour due to the lengthy hyperfocus of the male. This contention is supported by our observation, in that neither the proximity of the four observers (in the 2016 event) nor a brief period of photography (2001) disturbed the respective males. Risk of predation rises even more if, as in these examples, the behaviour occurs during daylight and in shallow water. 
Under some circumstances there might be potential gains from Davian behaviour as at least in the beaked toad (Rhinella proboscidea) necrophilic males may be able to squeeze eggs from dead females and fertilise them (Izzo et al., 2012). This occurrence may be rare as it has not been reported for other species. Our 2001 observation did include a small (20-25) number of ejected eggs at the cloaca of the female California red-legged frog. We made no attempt to determine if these eggs were fertilised. In the case of California red-legged frogs, however, females typically attach the egg mass to vegetation at or near the surface (Storer, 1925; Alvarez et al., 2013) in water that is, on average, $38 \mathrm{~cm}$ deep (Alvarez et al., 2013). In this case, the ejected eggs, which would typically number 2,000 to 6,000 , were resting on the hind legs of the dead female in water approximately $2 \mathrm{~cm}$ deep. If this small number of eggs were fertilised, we contend that the conditions were not appropriate for their development, resulting in no fitness gains for the male or female.

Alvarez (2011) reported male western toads, a sympatric species with California red-legged frog, in amplexus with a variety of objects, including a root ball, cattle dung, a dead conspecific, and a live female $R$. draytonii. Bateson (1983) suggested that an explosive breeding reproductive strategy, as in the western toad, may contribute to misdirected amplexus, including necrogamy (i.e., Davian behaviour). As the California red-legged frog is not considered an explosive breeder, it follows (sensu Bateson, 1983) that Davian behaviour would be expected to be less common in this species. Our temporally-spaced observations of Davian behaviour in 2001 and 2016, on a site where breedingseason California red-legged frog surveys are conducted annually, suggests that it is not common; we calculated a rate of observation at less than $0.0003 \%$. Alvarez (2011) suggested that temporally compressed breeding events, which periodically occur at this site due to prolonged drought, may result in increased breeding pressure from conspecifics and sympatric anurans, thereby contributing to misdirected amplexus behaviour (i.e., non-conspecifics) by males.

Inasmuch as Davian behaviour may represent an ecological trap for some individuals, it also represents a confounding stressor on a threatened species.

\section{ACKNOWLEDGEMENTS}

We thank N. Parizeau, P. Moldowan, and an anonymous reviewer for very helpful comments and assistance on the manuscript. We acknowledge the Contra Costa Water District, which allowed access to the site for these surveys and made these observations possible.

\section{REFERENCES}

Alvarez, J.A. (2011). Bufo boreas (Western Toad). Davian behavior. Herpetological Review 42: 408-409.

Alvarez, J.A., Cook, D.G., Yee, J.L., van Hattem, M.G., Fong, D.R. \& Fisher R.N. (2013). Comparative microhabitat characteristics as oviposition sites of the California redlegged frog. Herpetological Conservation and Biology 8: 539-551.

Ayres, C. (2010). Bufo bufo (Common Toad). Davian behavior. Herpetological Review 41: 192-193.

Bateson, P. (1983). Mate Choice. Cambridge University Press. New York, New York. 462 pp.

Bettaso, J., Haggarty, A. \& Russell, E. (2008). Rana boylii (Foothill yellow-legged frog). Necrogamy. Herpetological Review 39: 462.

Cortés Bedoy, S., Mantilla-Castaño, J.C. \& Pareja-Márquez, I.M. (2014). Necrophiliac and interspecific amplexus in Dendropsophus columbianus (Anura: Hylidae) in the Central Cordillera of Colombia. Herpetology Notes 7: 515516.

Costa, H.C., Silva, E.T., Campos, P.S., Oliveira, M.P.C., Nunes, A.V. \& Campos, P.S. (2010). The corpse bride: a case of Davian behaviour in the green Ameiva (Ameiva ameiva) in southeastern Brazil. Herpetological Notes 3: 79-83.

Dickerman, R.W. (1960). "Davian behavior complex" in ground squirrels. Journal of Mammalogy 41: 403.

Izzo, T.J., Rodrigues, D.J., Menin, M., Lima, A.P. \& Magnusson, W.E. (2012). Functional necrophilia: a profitable anuran reproductive strategy. Journal of Natural History 46: 4748.

Lehner, P.N. (1988). Avian Davian behavior. Wilson Bulletin 100: 293-294.

Magnhagen, C. (2003). Predation risk as a cost of reproduction. Trends in Ecology and Evolution 6: 183-186.

Pearl, C.A., Hayes, M.P., Haycock, R., Engler, J.D. \& Bowerman, J. (2005). Observations of interspecific amplexus between western North American ranid frogs and the introduced American bullfrog (Rana catesbeiana) and a hypothesis concerning breeding interference. American Midland Naturalist 154: 126-134.

Storer, T.I. (1925). A synopsis of the Amphibia of California. Berkeley: University of California Publications in Zoology 27: 1-342.

Accepted: 25 September 2020 